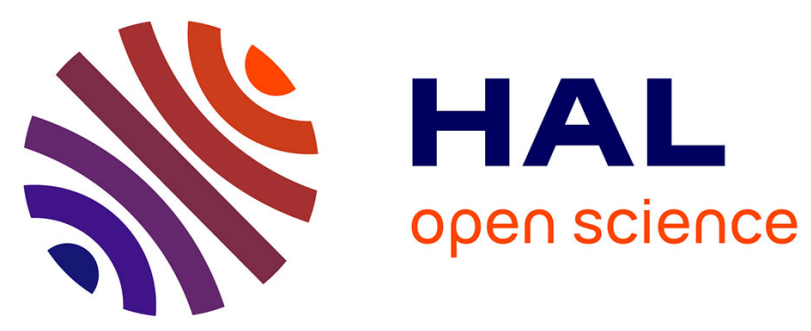

\title{
On the variation of regional $\mathrm{CO} 2$ exchange over temperate and boreal North America
}

Xia Zhang, Kevin Gurney, Philippe Peylin, Frederic Chevallier, Rachel Law, Prabir Patra, Peter Rayner, Christian Röedenbeck, Maarten Krol

\section{- To cite this version:}

Xia Zhang, Kevin Gurney, Philippe Peylin, Frederic Chevallier, Rachel Law, et al.. On the variation of regional CO 2 exchange over temperate and boreal North America. Global Biogeochemical Cycles, 2013, 27 (4), pp.991-1000. 10.1002/GBC.20091 . hal-02957432

\section{HAL Id: hal-02957432 \\ https://hal.science/hal-02957432}

Submitted on 6 May 2021

HAL is a multi-disciplinary open access archive for the deposit and dissemination of scientific research documents, whether they are published or not. The documents may come from teaching and research institutions in France or abroad, or from public or private research centers.
L'archive ouverte pluridisciplinaire HAL, est destinée au dépôt et à la diffusion de documents scientifiques de niveau recherche, publiés ou non, émanant des établissements d'enseignement et de recherche français ou étrangers, des laboratoires publics ou privés. 


\title{
On the variation of regional $\mathrm{CO}_{2}$ exchange over temperate and boreal North America
}

\author{
Xia Zhang, ${ }^{1}$ Kevin R. Gurney, ${ }^{1}$ Philippe Peylin, ${ }^{2}$ Frédéric Chevallier, ${ }^{2}$ Rachel M. Law, ${ }^{3}$ \\ Prabir K. Patra, ${ }^{5}$ Peter J. Rayner, ${ }^{4}$ Christian Röedenbeck, ${ }^{6}$ and Maarten $\mathrm{Krol}^{7}$ \\ Received 7 April 2012; revised 1 September 2013; accepted 9 September 2013; published 1 October 2013.
}

[1] Inverse-estimated net carbon exchange time series spanning two decades for six North American regions are analyzed to examine long-term trends and relationships to temperature and precipitation variations. Results reveal intensification of carbon uptake in eastern boreal North America (0.1 PgC/decade) and the Midwest United States (0.08 PgC/decade). Seasonal cross-correlation analysis shows a significant relationship between net carbon exchange and temperature/precipitation anomalies during the western United States growing season with warmer, dryer conditions leading reduced carbon uptake. This relationship is consistent with "global change-type drought" dynamics which drive increased vegetation mortality, increases in dry woody material, and increased wildfire occurrence. This finding supports the contention that future climate change may increase carbon loss in this region. Similarly, higher temperatures and reduced precipitation are accompanied by decreased net carbon uptake in the Midwestern United States toward the end of the growing season. Additionally, intensified net carbon uptake during the eastern boreal North America growing season is led by increased precipitation anomalies in the previous year, suggesting the influence of "climate memory" carried by regional snowmelt water. The two regions of boreal North America exhibit opposing seasonal carbon-temperature relationships with the eastern half experiencing a net carbon loss with near coincident increases in temperature and the western half showing increased net carbon uptake. The carbon response in the boreal west region lags the temperature anomalies by roughly 6 months. This opposing carbon-temperature relationship in boreal North America may be a combination of different dominant vegetation types, the amount and timing of snowfall, and temperature anomaly differences across boreal North America.

Citation: Zhang, X., K. R. Gurney, P. Peylin, F. Chevallier, R. M. Law, P. K. Patra, P. J. Rayner, C. Röedenbeck, and M. Krol (2013), On the variation of regional $\mathrm{CO}_{2}$ exchange over temperate and boreal North America, Global Biogeochem. Cycles, 27, 991-1000, doi:10.1002/gbc.20091.

\section{Introduction}

[2] The terrestrial biosphere plays a critical role in the global carbon cycle due to the fact that it sequestered roughly 2.6 PgC/yr over the decade of the 1990s [e.g., Le Quéré et al., 2009]. Quantitative understanding of the magnitude and

Additional supporting information may be found in the online version of this article.

${ }^{1}$ School of Life Sciences, Arizona State University, Tempe, Arizona, USA.

${ }^{2}$ Laboratoire des Sciences du Climate et de 1'Environment/IPSL, CEACNRS-UVSQ, Gif-sur-Yvette, France.

${ }^{3}$ Centre for Australian Weather and Climate Research, CSIRO Marine and Atmospheric Research, PMB 1, Aspendale, Victoria, Australia.

${ }^{4}$ Earth Sciences, University of Melbourne, Melbourne, Australia.

${ }^{5}$ Research Institute for Global Change, JAMSTEC, Yokohama, Japan.

${ }^{6}$ Max Planck Institute for Biogeochemistry, Jena, Germany.

${ }^{7}$ Wageningen University and Research Centre, Wageningen, Netherlands.

Corresponding author: X. Zhang, School of Life Sciences, Arizona State University, PO Box 874501, Tempe, AZ, USA. (Xia.Zhang11@asu.edu)

C2013. American Geophysical Union. All Rights Reserved. 0886-6236/13/10.1002/gbc.20091 variability associated with terrestrial net carbon exchange (NCE) is key to projecting future airborne $\mathrm{CO}_{2}$ concentrations and the feedbacks between the carbon cycle and the climate system [Field et al., 2007]. However, large uncertainty remains on the mechanistic drivers, the location and magnitude of NCE, and the way by which it interacts with climate [Friedlingstein and Prentice, 2010].

[3] The relationship between climate variation and the global carbon cycle was first noted in studies analyzing the interannual variability (IAV) of observed atmospheric $\mathrm{CO}_{2}$ concentration [Bacastow, 1976]. There is a general consensus in these studies that the observed $\mathrm{CO}_{2} \mathrm{IAV}$ is partly associated with the El Niño-Southern Oscillation (ENSO) [Schwalm et al., 2011; Keeling et al., 1995] and extreme disturbances such as drought-induced forest fires, insect epidemics [e.g., Langenfelds et al., 2002; Randerson et al., 2006], windstorms [e.g., Chambers et al., 2007], and enhanced diffuse radiation and surface cooling resulting from volcano-eruption aerosol loading [Lucht et al., 2002; Gu et al., 2003].

[4] Since the mid-1990s, a number of studies have utilized a variety of alternative methods to explore the relationship 


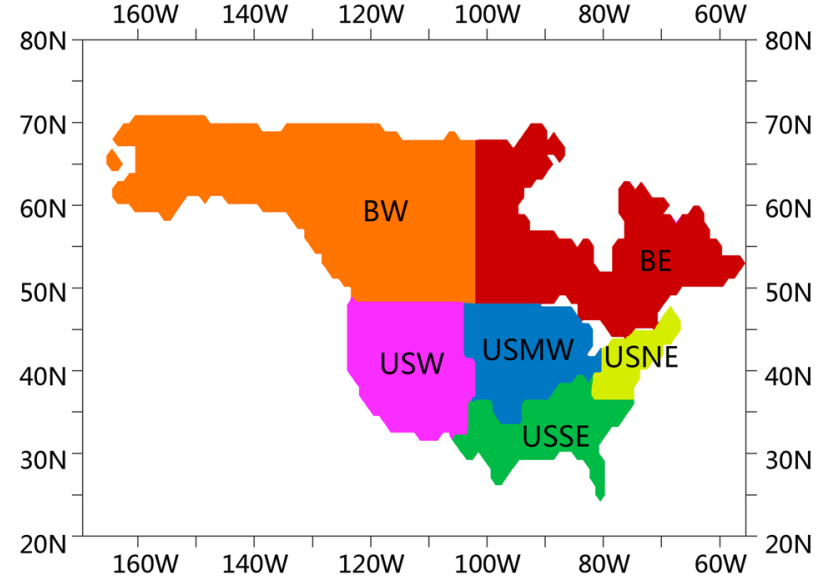

Figure 1. The six subcontinental regions analyzed in this study: Boreal West (BW), Boreal East (BE), US West (USW), US Midwest (USMW), US Northeast (USNE), and US Southeast (USSE).

between climate change and NCE. These include the use of terrestrial biosphere models (TBMs) [e.g., Kindermann et al., 1996; Ito and Oikawa, 2000], remote sensing measurements [e.g., Zhou et al., 2003], eddy covariance measurements [e.g., Mahecha et al., 2010; Yi et al., 2010], inversion analyses [e.g., Röedenbeck et al., 2003; Peylin et al., 2005], as well as tree ring records [Girardin et al., 2011]. These studies find that variations in climate affect NCE through modulation of photosynthesis and respiration, and that these impacts show not only latitudinal, regional, and ecosystem dependence, but temporal relationships. Though consensus is not absolute, most studies suggest that in low latitudes, the variations in NCE are dominated by precipitation anomalies [e.g., Schaefer et al., 2002; Zeng et al., 2005], those in the midlatitudes are constrained by both temperature and precipitation anomalies [Potter et al., 2003; Yi et al., 2010] while in the high latitudes they are mainly controlled by temperature anomalies [e.g., Schaefer et al., 2002; Piao et al., 2008]. Less agreement has been reached, however, on the quantitative sensitivity of the relationships between NCE and climate variability. At the global scale, Ito and Oikawa [2000] used terrestrial biosphere modeling to estimate that temperature anomalies account for $38 \%$ of NCE variations and precipitation accounts for roughly $19 \%$. In contrast, results from Schaefer et al. [2002] found that $44 \%$ of the NCE variability can be ascribed to precipitation while temperature accounts for $6 \%$. At the latitudinal and regional scale, a recent study using observations at eddy covariance sites suggested that $\sim 80 \%$ of the NCE variations can be explained by precipitation in the low versus temperate/boreal latitudinal bands [Yi et al., 2010].

[5] The relationship between NCE and climate variation within the specific domain of temperate and boreal North America (NA) has been reported on previously [e.g., Welp et al., 2007; Wang et al., 2011]. Despite the consensus that the NA terrestrial biosphere acts as a net carbon sink, uncertainty still remains regarding the size, spatial distribution, and interannual variation of this net uptake [e.g., Pacala et al., 2001; Goetz et al., 2005]. Over the past few decades, significant climate variability has been reported in the mid-to-high northern hemisphere and this climate variability has been reported to influence NA NCE through the growing season length and timing, soil moisture, and fire severity and frequency [e.g., Angert et al., 2005; Westerling et al., 2006]. Driven by a warming spring and longer growing season, increased net primary production (NPP) was detected for the decades of the 1980s and 1990s in northern high latitude in studies based on in situ observations, TBMs, and satellite remote sensing measurements [e.g., Lucht et al., 2002]. However, more recent studies proposed that this early spring carbon gain may be partly offset by carbon loss caused by drought-induced weakening of late summer and autumn NPP [Welp et al., 2007; e.g., Zhang et al., 2010].

[6] It should be pointed out that many of the TBMs and remote sensing measurement studies focus solely on the relationship between climate variability and gross carbon exchange (e.g., GPP, heterotrophic respiration) rather than the $\mathrm{NCE}$. In order to better quantify the relationship between atmospheric $\mathrm{CO}_{2}$ and interannually varying carbon exchange, the net flux is the critical quantity. Second, most of the studies focused on either large continental or forest plot spatial scales, with few addressing the regional scale. Motivated by these two limitations, we hypothesize that atmospheric $\mathrm{CO}_{2}$ inversion results can establish quantitative relationships between NCE and climate variations at the regional scale. Here, we present analysis of inverse-estimated monthly terrestrial NCE and their relationship to variations in the precipitation rate and temperature at the NA subcontinental scale for the 1984 to 2008 time period. The inverse-estimated carbon fluxes represent recent results from five participants in an ongoing TransCom intercomparison exercise. Using the results from five inversion systems, we construct deseasonalized time series of NCE for individual inversions as well as climate variables in six subcontinental NA regions. We analyze the NCE time series to determine regional trends and investigate the relationship between NCE and climate variations at interannual and seasonal temporal domains.

\section{Data and Methods}

\subsection{Construction of Subcontinental NCE}

[7] In this study, we focus on six NA subcontinental regions: two in Alaska and Canada and four in the temperate United States (US). Mexico is not considered in the inversion results due to the lack of observational constraint and the resulting unreliability of the results for this NA region. For Canada, we only consider the land area south of $\sim 71^{\circ} \mathrm{N}$ and divide the Canadian domain into two regions with a northsouth division at $101^{\circ} \mathrm{W}$ longitude. For the conterminous US, we focus on the four National Institute for Climatic Change Research (NICCR) regions. The regions are referred to as western boreal NA (BW), eastern boreal NA (BE), western United States (USW), midwestern United States (USMW), northeastern United States (USNE), and southeastern United States (USSE), as shown in Figure 1.

[8] Atmospheric $\mathrm{CO}_{2}$ inversions estimate $\mathrm{NCE}$ between the surface and atmosphere through inversion of atmospheric tracer transport. The NCE is derived by statistically minimizing the differences between simulated and observed atmospheric $\mathrm{CO}_{2}$ concentrations and the differences between the inverted NCE and prior information [Enting, 2002]. We define the NCE as the carbon exchange remaining after accounting for the fossil fuel flux. The sign convention used 
Table 1. Participating Inversion Models and Key Attributes

\begin{tabular}{|c|c|c|c|c|c|c|c|c|}
\hline Inversion Model & $\begin{array}{c}\text { No. } \\
\text { Regions }\end{array}$ & $\begin{array}{l}\text { Time } \\
\text { Period }\end{array}$ & $\begin{array}{l}\text { Obs. } \\
\text { Type }^{a}\end{array}$ & $\begin{array}{c}\text { Obs. } \\
\text { Stations }\end{array}$ & $\begin{array}{c}\text { IAV } \\
\text { Transport }\end{array}$ & $\begin{array}{l}\text { Inversion } \\
\text { Method }\end{array}$ & $\begin{array}{c}\text { Transport } \\
\text { Model }\end{array}$ & References \\
\hline C13 CCAM Law & 146 & $1992-2008$ & MM & $73 \mathrm{CO} 2,7 \mathrm{C} 13$ & No & Bayesian matrix & CCAM & Rayner et al. 2008 \\
\hline Jena_s93_v3. & Grid cell & $1991-2008$ & MM & 53 & Yes & Analytical & TM3 & Röedenbeck et al. 2003 \\
\hline Lsce var v1.0 & Grid cell & 1988-2008 & Raw & 128 & Yes & Analytical & LMDZv4 & Chevallier et al. 2010 \\
\hline C13_MATCH_Rayner & 116 & $1992-2008$ & MM & $73 \mathrm{CO} 2,7 \mathrm{C} 13$ & No & Bayesian matrix & MATCH & Rayner et al. 2008 \\
\hline Rigc_Patra & 64 & 1984-2006 & MM & 74 & Yes & Bayesian matrix & NIES/FRCGC & Patra et al. 2005 \\
\hline
\end{tabular}

aDetails about the property of inversion models are explained in the transcom section of supporting information. "MM" refers to monthly mean observed values. "Raw" refers to observations utilized at their original temporal resolution.

here has a negative NCE as carbon uptake or removal from the atmosphere and a positive NCE as carbon emission to the atmosphere. In this study, we use five atmospheric inversion results from the ongoing TransCom inversion exercise. The main objective of the current TransCom experiment is to quantify regional carbon fluxes using the latest inversion schemes with little central experimental prescription such as prior fluxes, observational networks, or inversion algorithms [Peylin et al., 2013, inversions.lsce.ips.fr/transcom] (see details in supporting information, section 1.0). Two criteria were employed to choose the inversion products used in this study. First, inversion results must span a period longer than 15 years. Second, the inversion results must be produced at relatively high spatial resolution. Some key features of the individual inversion setups are described in Table 1. A number of differences among the participating inversion systems are evident in the table. An analysis of how these differences determine the resulting NCE estimates across the models would require a separate study and has been partly accomplished in Peylin et al. [2013]. Thus, the focus in the present study emphasizes those results that exhibit consistency across the model set

[9] The NCE results from the participating inversion models were reported at varying spatial scales ranging from 1 to $5^{\circ}$ and with different grid corners. In order to ensure consistent regional definitions, the inversion outputs were interpolated onto a common $1^{\circ} \times 1^{\circ}$ grid and all results were aggregated up to the regions analyzed here (see supporting information section 2.0). The climate data used in this analysis include the $1.875^{\circ} \times 1.915^{\circ}$ monthly mean surface temperature (TEMP) and the monthly mean surface precipitation rate (PPTr) from NCEP-DOE AMIP-II Reanalysis [Kanamitsu et al., 2002]. The climate reanalysis results were also regridded onto a $1^{\circ} \times 1^{\circ}$ grid and then aggregated into the six North American subcontinental regions defined in this study as a means to ensure comparability to the NCE results.

\subsection{Analysis Methods}

[10] The focus of this study is to investigate the relationship between NCE and temperature/precipitation interannual anomalies. To obtain the anomaly time series, we first conducted a "deseasonalizing" process by removing the average seasonal signals from the monthly NCE and climate signals. Deseasonalization was performed using two different methods that emphasize different frequency domains of the time series. The first, a compact 13 month trapezoidal running mean, is constructed as follows:

$$
F_{i}^{\text {deseas }}=\left(\sum_{j=i-6}^{i+5} w_{j} F_{j}^{\text {mon }}+\sum_{j=i-5}^{i+6} w_{j} F_{j}^{\text {mon }}\right) / 2
$$

where $F_{i}^{\text {deseas }}$ is the deseasonalized variable (TEMP, PPTr, NCE) for month $i, F_{j}^{\text {mon }}$ is the original variable for month $j$, and $w_{j}$ accounts for varying month length. We refer to this as the "trapezoid-deseasonalized" time series and these time series are used to examine long-term trends (Figure 2).

[11] The second deseasonalization method utilized a "differencing" filter and was used to avoid the heightened autocorrelation that results from the trapezoid running
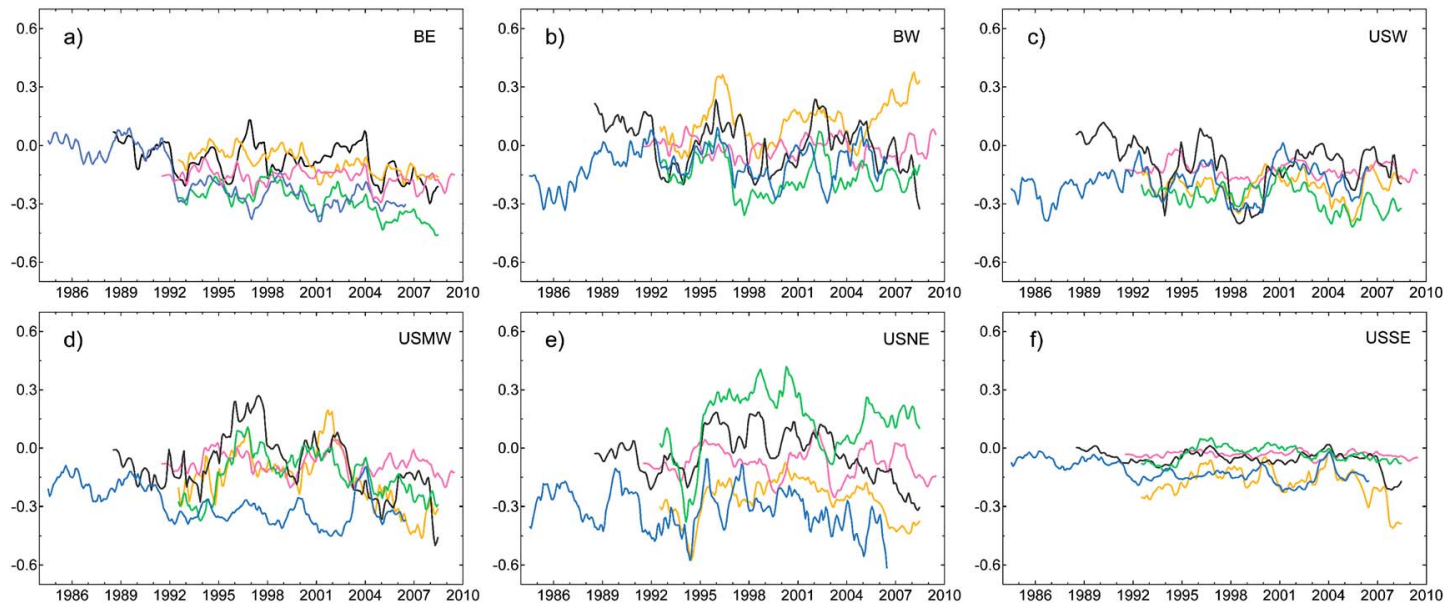

Figure 2. Trapezoid-deseasonalized monthly regional $\mathrm{NCE}\left(\mathrm{PgC} \mathrm{yr}^{-1}\right)$ time series from the participating inversion models: C13_CCAM_Law (orange); Jena_s93_v3.2 (pink); C13_MATCH_Rayner (green); LSCE_var_v1.0 (black); Rigc_Patra (blue). 

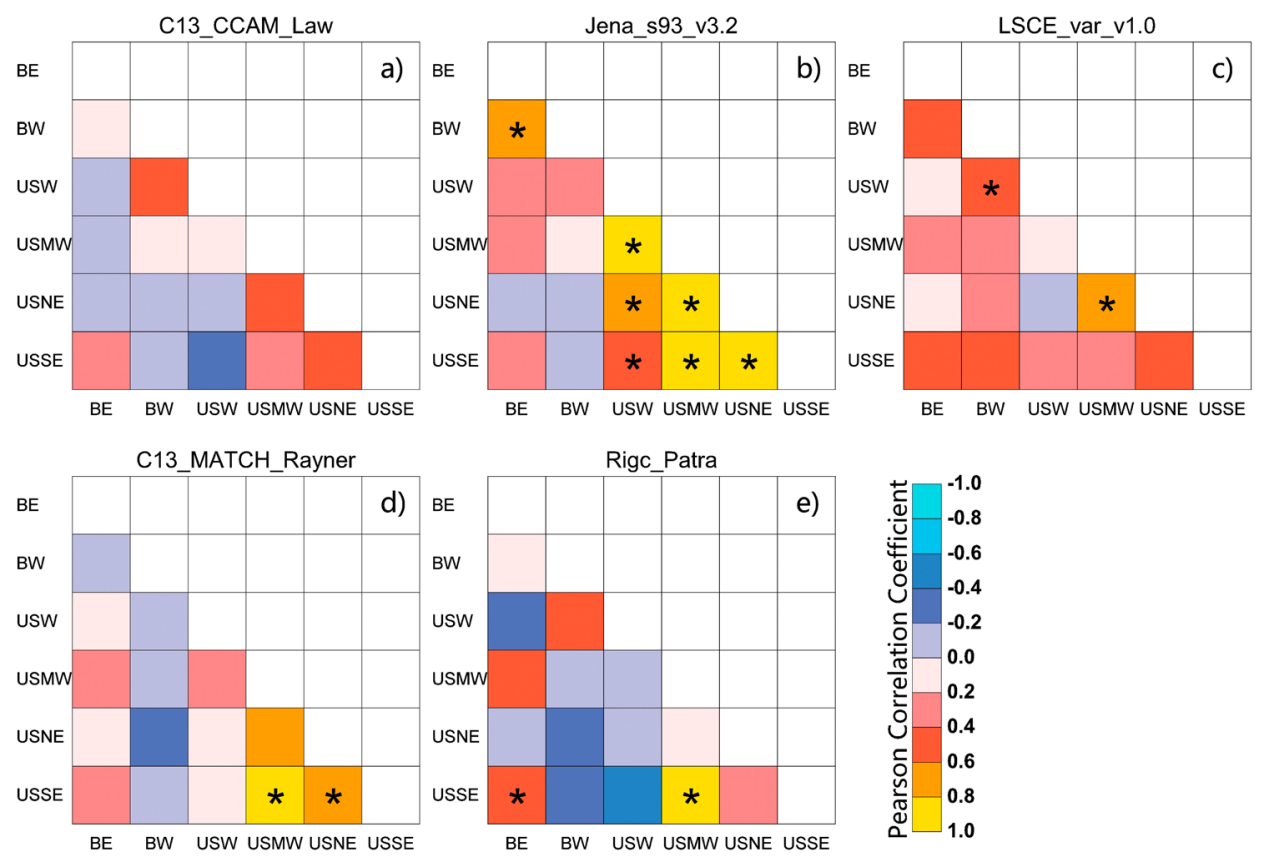

Figure 3. Regional cross-correlation Pearson $r$ values for the TLD-normalized NCE time series for each participating inversion model. Regional correlations marked with * are statistically significant $(p<0.05)$.

mean and is better at isolating higher frequency (seasonal) variations. This second deseasonalization is performed by subtracting a long-term mean annual stationary cycle from the complete multiyear time series. Both deseasonalization methods were further processed to simplify analysis. First, they were detrended by subtracting their own least-squaresfit straight line. Then, standardization was conducted to adjust the time series to a zero mean and transform the variables into units of standard deviations. This allows for the relationships to focus on the variations without being tied to the absolute units of either the fluxes or the climate variables.

[12] We refer to the resulting time series from these two different deseasonalization and normalization processing as "TLD normalized" (trapezoidal deseasonalization, removal of long-term mean, detrended and standardized) and "SLD normalized" (differencing deseasonalization, removal of long-term mean, detrended and standardized). The TLDnormalized time series (supporting information, Figure S3.1) is used to investigate the relationship between variations in NCE and variations in TEMP/PPTr using a lagged Pearson product-moment correlation analysis (lag/lead time periods range from -12 to 12 months).

[13] The SLD-normalized time series (supporting information, Figure S3.2), by contrast, is used to investigate higher frequency (seasonal anomalies) relationships between the NCE and TEMP/PPTr. The time series are composited into 12 separate time series representing each calendar month with an additional 3 month triangular running smoother to remove higher frequency variations (subseasonal noise) embedded in the signal:

$$
F_{k}=\left(\sum_{i=k-1}^{k+1} w_{i} F_{k}^{a n o m}\right) / 2
$$

where $F_{k}$ is the filtered variable for month $k, F_{k}^{\text {anom }}$ is the anomalous signal for month $k$, and $w_{i}$ is weight for month $i \quad\left(w_{k-1}=0.5 ; w_{k}=1 ; w_{k+1}=0.5\right)$. A stationary cross-correlation analysis is then utilized, where we focus on relationships centered on each month of the calendar year representing the Pearson product-moment correlation for all 3 month combinations.

[14] The statistical significance of all correlation coefficients is assessed using the two-tailed $t$-statistic with a significance level of 0.05 . We also account for the serial correlation (i.e., autocorrelation) in the time series to more accurately assess the statistical significance. Serial correlation is frequently present in geophysical time series due to inertia or carryover processes in the physical system, and often enhanced by the application of a low-pass filter. Hence, the number of effective degrees of freedom of the time series is estimated using the methods of Bretherton et al. [1999].

[15] Previous inversion studies have shown that the estimated fluxes are sensitive to the spatial resolution of the inversion, the chosen $\mathrm{CO}_{2}$ observing network, prior flux information, and the atmospheric transport model [Gurney et al., 2002; Law et al., 2003; Patra et al., 2006; Baker et al., 2006; Gurney et al., 2008]. These factors, in addition to a paucity of observation sites to constrain regional $\mathrm{NCE}$ and aggregation from the pixel-domain to subcontinental regions, may lead to results that are not regionally independent. To assess if the regional results suffer from a lack of regional independence, we examine the inversion-specific, interregion correlations for the TLD-normalized NCE time series (Figure 3). The correlation coefficients show a wide range for each inversion, with few statistically significant $(p<0.05)$ interregion correlations. In the figure, none of correlations for the C13_CCAM_Law inversion are statistically significant. Three inversions show statistically significant correlations between two-pair regions. For the Jena_s93_v3.2 inversion, 7 out of the 15 interregional correlations show statistically significant correlations.

[16] Other than the Jena_s93_v3.2 inversion, the results suggest that most of the individual region/inversion NCE time series can be treated as independent though caution 
Table 2. Slope of Deseasonalized NCE for Individual Models Over Each Region ${ }^{\mathrm{a}}$

\begin{tabular}{lcccccc}
\hline Inversion Model & BE & BW & USW & USMW & USNE & USSE \\
\hline C13_CCAM_Law & $-\mathbf{0 . 0 0 9}$ & 0.008 & 0.00 & $\mathbf{- 0 . 0 1 4}$ & -0.001 & $\mathbf{- 0 . 0 0 4}$ \\
Jena_s93_v3.2 & $-\mathbf{0 . 0 0 3}$ & -0.001 & -0.001 & $-\mathbf{0 . 0 0 2}$ & -0.002 & $-\mathbf{0 . 0 0 1}$ \\
Lsce_var_v1.0 & $-\mathbf{0 . 0 0 7}$ & $-\mathbf{0 . 0 0 6}$ & $-\mathbf{0 . 0 0 7}$ & $-\mathbf{0 . 0 0 7}$ & $-\mathbf{0 . 0 0 5}$ & $-\mathbf{0 . 0 0 3}$ \\
C13_MATCH_Rayner & $-\mathbf{0 . 0 1 1}$ & -0.003 & $-\mathbf{0 . 0 0 6}$ & -0.003 & 0.007 & -0.001 \\
Rigc_Patra & $\mathbf{- 0 . 0 1 7}$ & $\mathbf{0 . 0 0 4}$ & $\mathbf{0 . 0 0 3}$ & $\mathbf{- 0 . 0 0 9}$ & $-\mathbf{0 . 0 0 5}$ & $\mathbf{- 0 . 0 0 5}$ \\
\hline
\end{tabular}

${ }^{\mathrm{a}}$ In the table, bold values are significant at $<0.01$. (unit: $\mathrm{PgC} / \mathrm{yr}^{2}$ ).

must be exercised in interpreting the regional results, particularly the USSE region which shows the greatest incidence of interregional correlation, due primarily to the scarcity of observing stations.

\section{Results and Discussion}

\subsection{NCE Trends}

[17] Figure 3 depicts the trapezoid-deseasonalized monthly NCE for the individual inversions in the six subcontinental regions and Table 2 shows the results of the trend analysis. A statistically significant increase in net carbon uptake is found for all inversions in the $\mathrm{BE}$ region (model mean: $-0.1 \mathrm{PgC} /$ decade) and for four models in the USMW region (four model mean: $-0.08 \mathrm{PgC} /$ decade) during the investigated time period. Similarly, a small negative trend is also found in the USSE region for four inversions. In the remaining three regions, the results either contain conflicting trend directions or are not statistically significant.

[18] The increasing carbon uptake for the BE region in this study is supported by Hicke et al. [2002], in which they proposed that increased precipitation and recovery from insect damage would lead to increased net carbon uptake in the eastern Canada region. Other studies also reported an intensified growing season carbon uptake in boreal NA, but ascribed it to a progressively warmer spring and longer growing season
[Myneni et al., 1997; Lucht et al., 2002]. Increasing carbon uptake was also reported in the US Midwest and east coast, linked to climate trends and changes in anthropogenic activity (e.g., altered fertilization, irrigation, and crop choices) [Nemani et al., 2002; Hicke et al., 2002; Lobell et al., 2002].

[19] To explore the association between the NCE trends and climate trends, we tested the NCE trends against temperature and precipitation rate using multivariate linear regression analysis (see supporting information, section 4.0). Our results did not find any consistent, statistically significant associations between the regional NCE and climate trends. This may be due to the limitations of the length of the available NCE time series.

\subsection{NCE - Climate Anomaly Relationships}

[20] Previous work has established that the IAV is a more robust result from inversion studies when compared to the long-term mean and this is driven primarily by the larger signal to noise available in observed $\mathrm{CO}_{2}$ for time variations (used to drive IAV NCE) versus spatial gradients (used to drive long-term mean NCE) [Baker et al., 2006; Gurney et al., 2008]. In the analysis that follows, we identify positive correlations as instances where NCE and climate anomalies move in the same direction (both positive or both negative) while a negative correlation reflects instances in which they move in opposing directions (one positive with the other negative and vice versa).

\subsubsection{Interannual Lagged Correlations}

[21] Figure 4 presents the lagged correlation results between the inversion-specific, TLD-normalized regional NCE time series and the two TLD-normalized PPTr and TEMP. For the PPTr variable, four of the five models show statistically significant negative correlations (four model mean $r=-0.64$ ) in the USW region with maximum positive (negative) NCE anomalies following negative (positive) PPTr anomalies at a lag of one to eight months. Given the results for the USW region in Figure 2, this would suggest that short-term precipitation

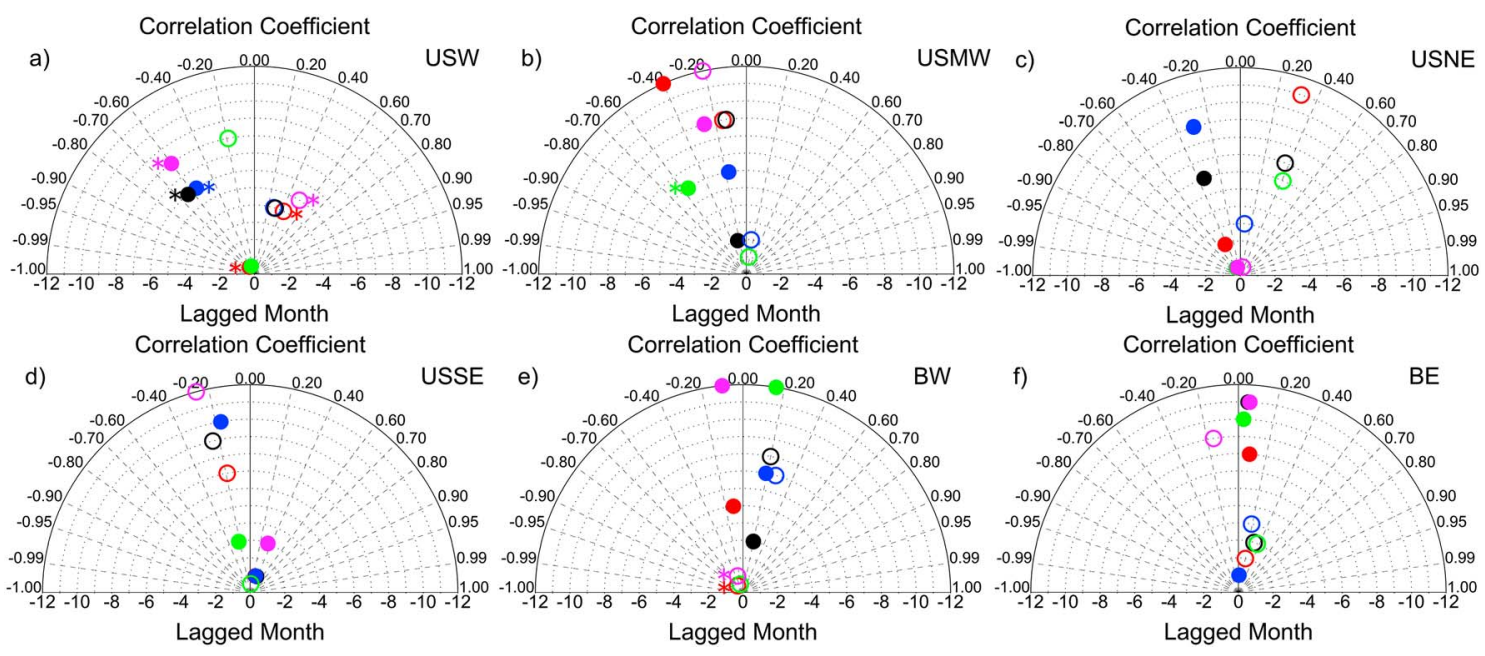

Figure 4. Magnitude and timing of the maximum lagged correlation between the TLD-normalized regional NCE anomalies and the TLD-normalized regional TEMP/PPTr anomalies for participating inversion models. TEMP is represented by open symbols and PPTr is represented by closed symbols. The $x$ axis values ("Lagged Month") refer to the number of months that the NCE anomalies follow TEMP/PPTr anomalies. C13_CCAM_Law (pink); Jena_s93_v3.2 (red); C13_MATCH_Rayner (green); LSCE_var_v1.0 (black); Rigc_Patra (b) blue). Symbols marked with * denote statistically significant correlations $(p \overline{<}<\overline{0} \overline{0})$. 

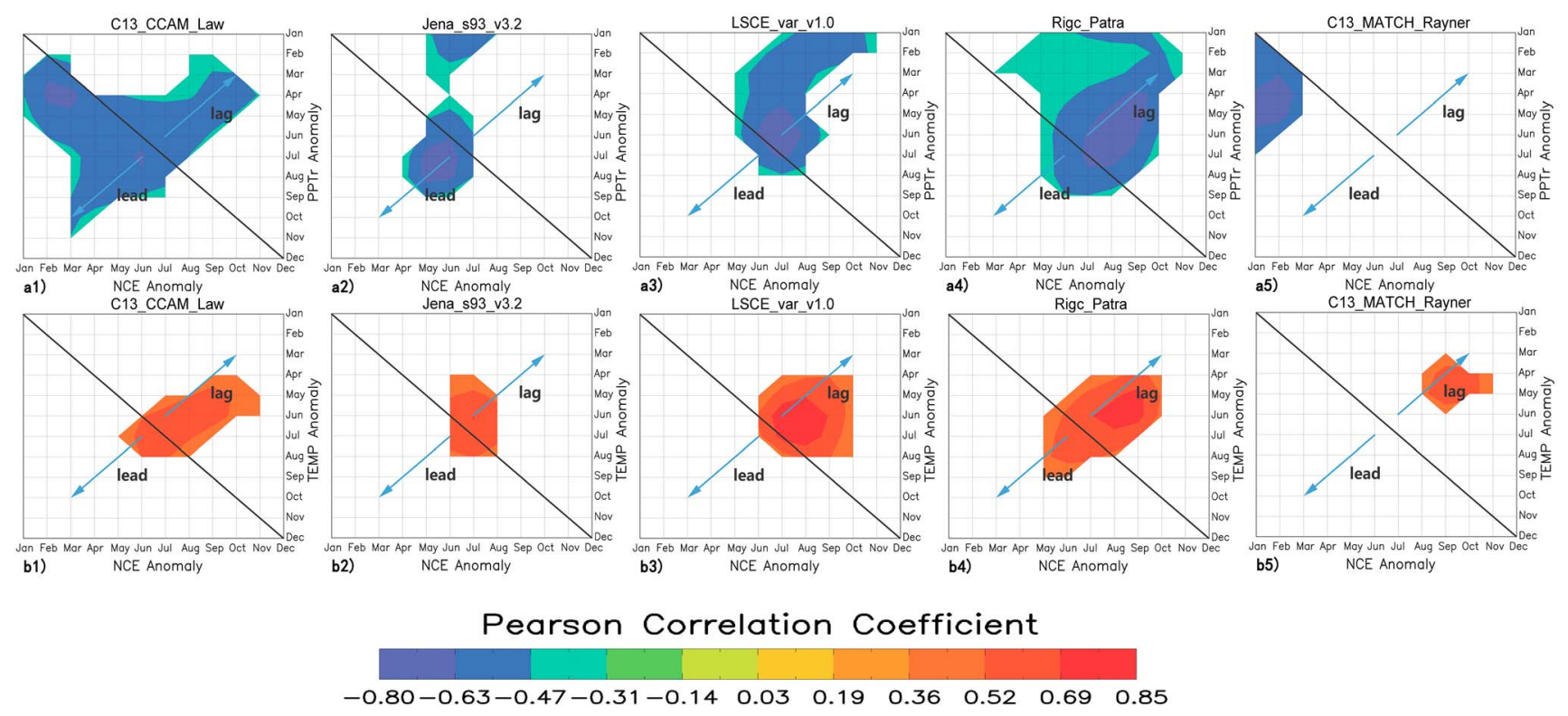

Figure 5. USW seasonal cross correlation between regional SLD-normalized NCE anomalies and a1) to a5) SLD-normalized PPTr anomalies and b1) to b5) SLD-normalized TEMP anomalies from each of the participating inversion models. Only results that are statistically significant $(p<0.05)$ are displayed.

increases are followed by increased carbon uptake and vice versa. We also find a positive (though weak) maximum correlation between NCE and TEMP for the USW region in two of the five models with a lag of four to eight months. Three of the five models exhibit a statistically significant relationship between the BW NCE and TEMP anomalies with a negative maximum correlation (three model mean $r=-0.63$ ) at a one to eight month lag, suggesting increased carbon uptake following increases in temperature. The remaining regional correlations between the NCE and TEMP/PPTr anomalies are not statistically significant. The lack of agreement and the limited significance of the few relationships that do emerge from the complete interannual time series using the TLD normalization suggest that a closer examination using seasonal cross correlations may uncover climate-carbon feedbacks.

\subsubsection{Seasonal Cross Correlations}

[22] Cross-correlation analysis offers more insight into the relationships between the NCE and the climate variables by examining correlations at specific seasons. Figures 5-8 present the seasonal cross-correlation analysis between the SLDnormalized NCE and PPTr/TEMP anomalies for the USW, USMW, BE, and BW regions, respectively. The USSE and USNE regions show little to no statistically significant correlation results and hence are not shown. Instances in which
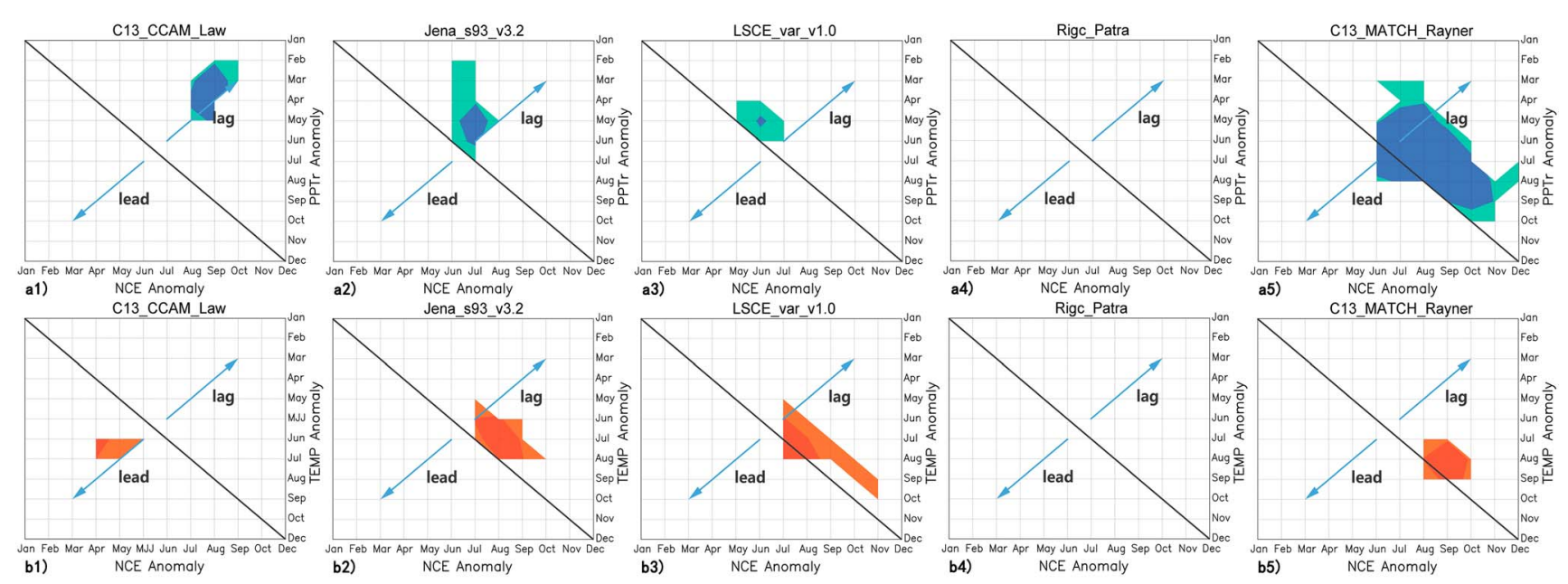

Pearson Correlation Coefficient

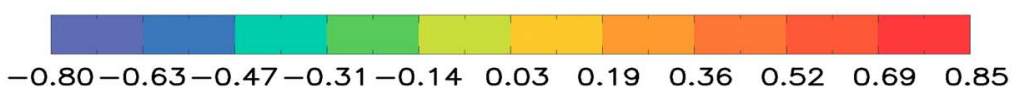

Figure 6. USMW seasonal cross correlation between regional SLD-normalized NCE anomalies and a1) to a5) SLD-normalized PPTr anomalies and b1) to b5) SLD-normalized TEMP anomalies from each of the participating inversion models. Only results that are statistically significant $(p<0.05)$ are displayed. 

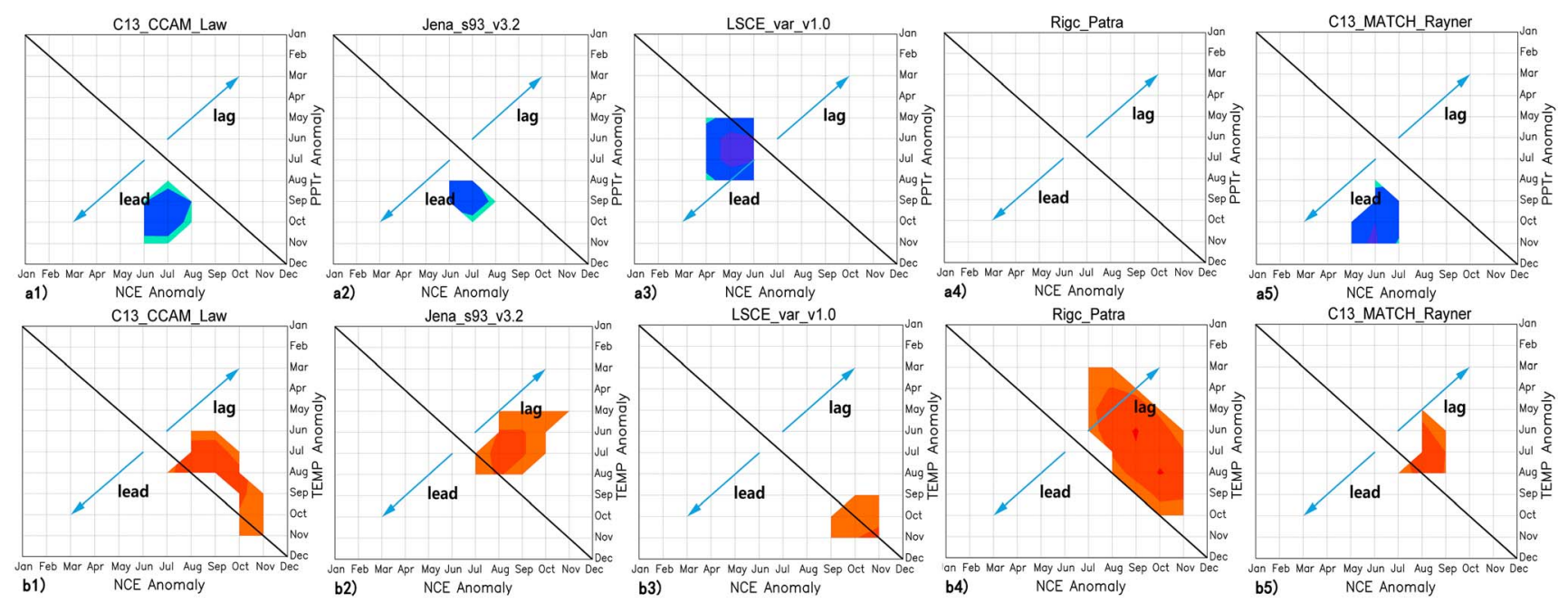

a4) NCE Anomaly
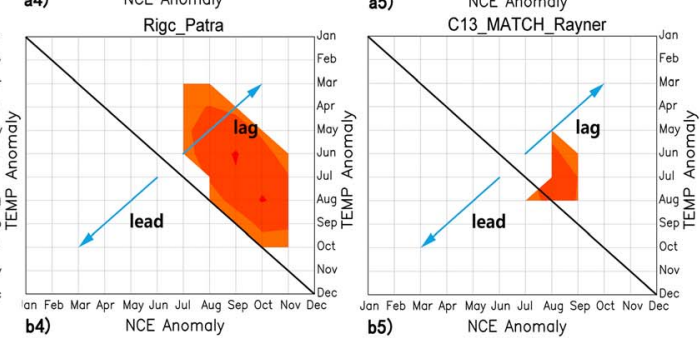

Pearson Correlation Coefficient

$\begin{array}{llllllll}-0.80-0.63-0.47-0.31-0.14 & 0.03 & 0.19 & 0.36 & 0.52 & 0.69 & 0.85\end{array}$

Figure 7. BE seasonal cross correlation between regional SLD-normalized NCE anomalies and a1) to a5) SLD-normalized PPTr anomalies and b1) to b5) SLD-normalized TEMP anomalies from each of the participating inversion models. Only results that are statistically significant $(p<0.05)$ are displayed.

NCE anomalies lead climate anomalies are due to (1) biased timing in inversion model results, (2) correlations that have no mechanistic relationships, and (3) NCE anomalies that lag climate anomalies by greater than one year, which in this analysis will show up as a lead instead of a lag. For example, a previous study by Bunn et al. [2007] quantified NCE anomalies driven by PPTr anomalies over the BE region and found lags greater than one year.

[23] In the USW region, all inversions exhibit a negative NCE-PPTr correlation (model mean $r=-0.71$ ) suggesting that increases in the precipitation rate (positive PPTr anomalies) are accompanied by intensification of net carbon uptake (negative NCE anomalies), and vice versa (Figure 5a). However, the timing of the correlation between the NCE and PPTr varies among the inversions. Two of the inversions show winter NCE anomalies leading the winter PPTr anomalies by one to two months. The remaining three inversions exhibit spring/summer NCE anomalies with one to two month leads and lags relative to the spring/summer PPTr anomalies. The C13_CCAM_Law also exhibits a broad maximum negative correlation spanning a 9 month lag to a 9 month lead. The roughly coincident spring/summer NCEPPTr relationship suggests an enhancement of spring/summer rainfall that stimulates increases in net carbon uptake (photosynthetic uptake overcoming respiration release) during the growing season. Similarly, the relationship also implies that episodes of drought are followed by lessened photosynthetic uptake during the growing season.

[24] The two different seasonal relationships exhibited by subsets of the inversions may reflect the variation in seasonal timing of the vegetation mix in the western US. For example, the US Southwest contains Mediterranean and desert biomes that are less active during summer months versus winter and hence "green up" following winter rainfall anomalies $[\mathrm{Hu}$ and Feng, 2004]. Hence, the presence of a winter NCEPPTr correlation in two of the inversions may be due to
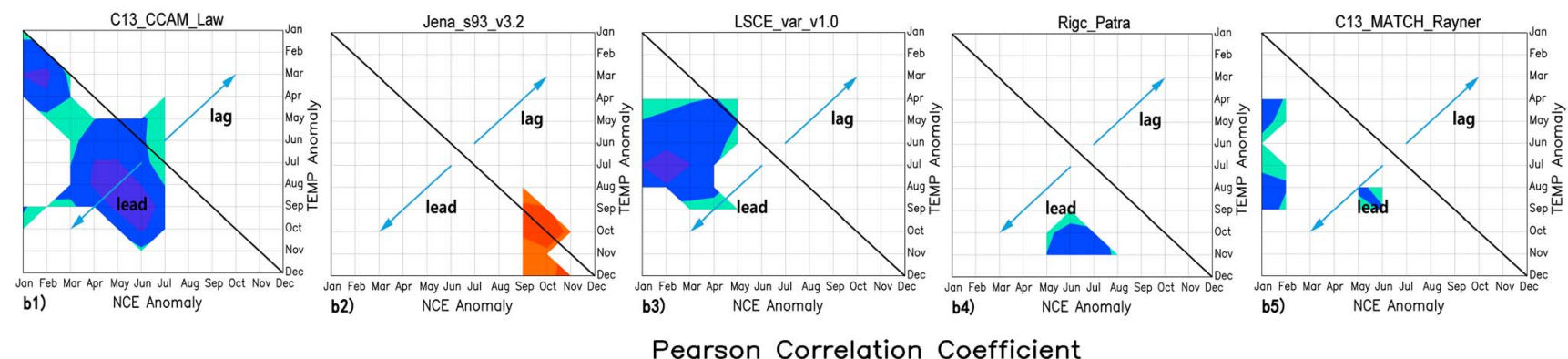

Pearson Correlation Coefficient

$\begin{array}{lllllll}-0.80-0.63-0.47-0.31-0.14 & 0.03 & 0.19 & 0.36 & 0.52 & 0.69 & 0.85\end{array}$

Figure 8. BW seasonal cross correlation between regional SLD-normalized NCE anomalies and SLDnormalized TEMP anomalies from each of the participating inversion models. Only results that are statistically significant $(p<0.05)$ are displayed. 
atmospheric transport that emphasizes the Southwestern portions of the USW region.

[25] A significant positive NCE-TEMP relationship is evident for the USW region (Figure 5b). All five inversions show a positive correlation (model mean $r=0.70$ ), with summer/fall NCE anomalies following spring/summer TEMP anomalies. The positive correlation between NCE and temperature anomalies could suggest either increasing carbon release (respiration or fire) or weakened photosynthesis accompanying higher temperatures, and vice versa. Research utilizing NDVI measurements proposed a decline in carbon uptake in mid- to high latitudes due to warmer and drier summers [Angert et al., 2005]. However, other studies that have examined both photosynthesis and respiration response to temperature in the US West have concluded that respiration is more sensitive [Allen et al., 2005; Anderson-Teixeira et al., 2010] and that higher temperatures increase ecosystem carbon loss from the decomposition of dead plant material [Kirschbaum, 1995].

[26] Both the NCE-TEMP and NCE-PPTr relationships in the USW are consistent with the impacts of drought, which are associated with elevated temperature and reduced precipitation [McDowell et al., 2008]. There has been a welldocumented increase in the duration, intensity, and frequency of drought in the USW which has been referred to as "global change-type droughts" [Breshears et al., 2005]. Higher temperatures and reduced water availability increase the energy load and water stress on vegetation, which result in greater vegetation mortality. Furthermore, this can also lead to greater amounts of dry woody material that is susceptible to bark-beetle infestations and wildfires, which have also been increasing in frequency and duration in the USW since the mid-1980s [Westerling et al., 2006; van Mantgem et al., 2009]. This drought-vegetation relationship is consistent with the NCE correlations found here for the USW. For example, negative PPTr anomalies during the extreme 19992004 drought period are correlated (model mean: $r=-0.68$ ) with positive NCE anomalies in the USW region at lags of $\sim 6$ months. Climate change projections for the USW suggest that vegetation will experience more water stress because of the effects of higher temperature on evaporation rates [Seager, 2007]. Our findings suggest that warmer and drier conditions will result in greater carbon emissions, and that the combined effect has the potential to reduce carbon stocks and net ecosystem productivity in the USW region.

[27] In the USMW region, a negative NCE-PPTr correlation (four model mean $r=0.60$ ) is found for four models, with summer/fall NCE anomalies following spring/summer precipitation anomalies (Figure 6a). The negative NCE-PPTr correlation indicates that enhanced spring/summer rainfall results in greater net carbon uptake during the growing season, and vice versa. This is supported by Lu et al. [2010], which found that precipitation increases cause greater NPP over the USMW. For the NCE-TEMP relationship, a positive correlation (four model mean $r=0.6$ ) is found for four models (Figure 6b). Three models show summer/fall NCE anomalies following summer TEMP anomalies, while one (C13_CCAM_Law) indicates a lead relationship. The positive NCE-TEMP correlation implies that increased temperature anomalies lead to weakened photosynthetic uptake during the growing season, and vice versa. However, given the discrepancy in the timing of the NCE-TEMP relationship in the USMW, this result is ambiguous.
[28] In the BE region, a negative correlation is found between the NCE and PPTr anomalies for four inversions (four model mean $r=-0.60$ ) (Figure 7a). However, the timing of the relationship varies. Three inversions show summer NCE anomalies following fall PPTr anomalies in the previous year. One inversion shows spring NCE anomalies following summer PPTr anomalies in the previous year. The negative NCE-PPTr correlation suggests that PPTr increases intensify carbon uptake during the growing season and vice versa, and that this response lags the PPTr anomalies by almost one year. This relationship suggests that increased precipitation (snowpack) in fall influences conditions in the following summer through ground ice and soil freeze-thaw processes [Schaefer et al., 2007; Matsumura and Yamazaki, 2012]. The resulting increase in the growing season water table depth and water availability inhibits nighttime respiration leading to increased net carbon uptake [Dunn et al., 2007]

[29] The NCE anomalies are positively correlated (model mean $r=0.65$ ) to TEMP anomalies for all inversions in the $\mathrm{BE}$ region, with summer/fall NCE anomalies following close behind summer TEMP anomalies (Figure 7b). The positive association indicates that increases in temperature weaken net carbon uptake and vice versa. This finding is consistent with the study of Piao et al. [2008], in which they suggest that autumn warming would cause a greater response to respiration than photosynthesis, thus leading to a decline in net carbon uptake.

[30] In the BW region, however, our analysis does not show any significant NCE-PPTr relationship. Other studies have found that increased water content suppressed NCE in western boreal black spruce forests in the late summer and fall [Krishnan et al., 2009]. This discrepancy may be ascribed to the diversity of plant types in this region as well as their difference in responding to climate variability [Goetz et al., 2005]. By contrast, NCE anomalies for the $\mathrm{BW}$ region are negatively correlated to TEMP (four model mean $r=-0.68$ ) in four of the five inversions, with winter/ spring NCE anomalies correlated to summer/fall TEMP anomalies (Figure 8). This negative NCE-TEMP correlation implies that enhanced winter/spring carbon uptake responds to a warmer summer/fall time period in the previous year. These findings for the BW region are consistent with previous studies using both satellite remote sensing and field observations. For example, studies based on multidecadal NDVI data proposed a "greening" photosynthetic trend in high latitudes, which is tied to spring/early summer shrub expansion in tundra ecosystems [e.g., Bunn et al., 2007]. A number of recent studies indicate that the shrub expansion appears mainly in Alaska and western Canada, which is linked to greater early growing season carbon uptake driven by winter and spring warming [Welp et al., 2007]. Some studies have found this northward shrub expansion correlated to summer warming in the previous year, consistent with the BW negative NCE-TEMP relationship found here [Blok et al., 2011].

[31] Why does an NCE-TEMP dipole relationship appear in the two boreal regions in the context of widespread warming in the northern latitudes, as suggested by the results presented here? This could be driven by vegetation in the two regions responding similarly to temperature variations but that the two regions exhibit an opposing temperature variation. Alternatively, the two regions may have the 
same temperature variation, but the vegetation response to temperature in the two regions exhibit an opposing response. Finally, a combination of the two may be occurring.

[32] An examination of the SLD-normalized TEMP anomalies in the two regions does indeed show dipole behavior (Figure S3.3, in supporting information) supporting the notion that the relationship has to do with the regional climate variations. For example, Wang et al. [2011] found that opposing temperature variations in the two regions drove the Spring/Summer between NPP and temperature using 15 years of NDVI. These opposing temperature anomalies may be driven themselves by snowpack anomalies and the impact they have on surface temperatures.

[33] However, ecosystem structure is also likely an important factor in the dipole NCE-temperature relationship. The $\mathrm{BW}$ region is predominantly tundra while the $\mathrm{BE}$ region is predominantly forest [Zhang et al., 2008]. Hence, a vegetation-specific response to temperature anomalies may play a role [Goetz et al., 2005; Zhang et al., 2008]. The precise mixture of vegetation response versus climate variation in boreal NA remains a topic of future study.

\section{Conclusions}

[34] Subcontinental-scale net carbon exchange (NCE) time series were constructed for six North American regions based on five atmospheric $\mathrm{CO}_{2}$ inversions across the 1984 to 2008 time period. The magnitude and spatial pattern of the regional NCE were analyzed and relationships to temperature and precipitation rate explored. A statistically significant increase in net carbon uptake is found for all inversions in the BE (model mean: $-0.1 \mathrm{PgC} /$ decade) and the USMW regions (model mean: $-0.08 \mathrm{PgC} /$ decade) during the investigated time period. Seasonal cross-correlation analysis reveals significant NCE anomalies correlated to precipitation and temperature anomalies in the USW region during the growing season, with less precipitation and warmer temperatures correlating with reduced NCE. The associations suggest that drought is an important controlling mechanism in this region. The relationships are consistent with the impacts of "global changetype droughts" that are associated with elevated temperature and reduced precipitation. These events increase vegetation mortality and wildfire occurrence through the availability of dry, woody material. The findings here support the contention that climate change may increase carbon loss in the USW. Similar relationships were found in the USMW region, with rising temperatures and less precipitation correlated to reduced net carbon uptake in the late growing season, and vice versa. Temperature anomalies are revealed to impact the NCE in the growing season in BW and BE. For the $\mathrm{BW}$ region, a warmer Summer/Fall in the previous year is followed by increased carbon uptake in the following Winter/ Spring. By contrast, increased temperature anomalies are found to coincide with reduced carbon uptake in the growing season in BE. The dipole NCE response to temperature anomalies may result from a combination of differing regionally dominant vegetation, regional differences in the amount and timing of snowpack anomalies and opposing temperature anomalies. Additionally, precipitation anomalies are shown to be significantly associated with NCE anomalies in the BE, suggesting that increased precipitation (snow) in previous fall and winter drives enhanced growing season carbon uptake of the following year. Differences in the response of NCE to climate variations in the boreal regions reveal the complexity of high-latitude carbon dynamics and the need for further research.

[35] Acknowledgments. DOE supported this research on subaward MPC 35WY. PKP is partly supported by JSPS/MEXT KAKENHI-A and GRENE.

\section{References}

Allen, A. P., J. F. Gillooly, and J. H. Brown (2005), Linking the global carbon cycle to individual metabolism, Funct. Ecol., 19, 202-213.

Anderson-Teixeira, K. J., J. P. Delong, A. M. Fox, D. A. Drese, and M. E. Litvak (2010), Differential responses of production and respiration to $\mathrm{T}$ and moisture drive the carbon balance across a climatic gradient in New Mexico, Glob. Change Bio., 17, 410-424.

Angert, A., S. Biraud, C. Bonfils, C. C. Henning, W. Buermann, J. Pinzon, C. J. Tucker, and I. Fung (2005), Drier summers cancel out the $\mathrm{CO}_{2}$ uptake enhancement induced by warmer springs, Proc. Natl. Acad. Sci. U. S. A., $102,10,823-10,827$.

Bacastow, R. B. (1976), Modulation of atmospheric carbon dioxide by the Southern Oscillation, Nature, 261, 116-118.

Baker, D. F., et al. (2006), TransCom 3 inversion intercomparison: Impact of transport model errors on the interannual variability of regional $\mathrm{CO}_{2}$ fluxes, 1988-2003, Global Biogeochem. Cycles, 20, GB1002, doi:10.1029/ 2004GB002439.

Blok, D., G. Schaepman-Strub, H. Bartholomeus, M. M. P. D. Heijmans, T. C. Maximov, and F. Berendse (2011), The response of Arctic vegetation to the summer climate: Relation between shrub cover, NDVI, surface albedo and temperature, Environ. Res. Lett., 6, doi:10.1088/1748-9326/6/ 3/035502.

Breshears, D. D., et al. (2005), Regional vegetation die-off in response to globalchange-type drought, Proc. Natl. Acad. Sci. U. S. A., 102, 15,144-15,148.

Bretherton, C. S., M. Widmann, V. P. Dymnikov, J. M. Wallace, and I. Blade (1999), The effective number of spatial degrees of freedom of a timevarying field, J. Clim., 12, 1990-2009.

Bunn, A. G., S. J. Goetz, J. S. Kimball, and K. Zhang (2007), Northern highlatitude ecosystems respond to climate change, EOS Trans. AGU, 88, 333-340.

Chambers, J. Q., J. I. Fisher, H. Zeng, E. L. Chapman, D. B. Baker, and G. C. Hurtt (2007), Hurricane Katrina's carbon footprint on U.S. gulf coast forests, Science, 318, 1107-1107.

Chevallier, F., et al. (2010), $\mathrm{CO}_{2}$ surface fluxes at grid point scale estimated from a global 21-year reanalysis of atmospheric measurements, J. Geophys. Res., 115, D21307, doi:10.1029/2010JD013887.

Dunn, A. L., C. C. Barford, S. C. Wofsy, M. L. Goulden, and B. C. Daube (2007), A long-term record of carbon exchange in a boreal black spruse forest: means, responses to interannual variability and decadal trends, Glob. Change Biol., 13, 577-590.

Enting, I. (2002), Inverse Problems in Atmospheric Constituent Transport, Cambridge Univ. Press, New York

Field, C. B., D. B. Lobell, H. A. Peters, and N. R. Chiariello (2007), Feedbacks of terrestrial ecosystems to climate change, Annu. Rev. Environ. Resour., 32, 1-29, doi:10.1146/annurev.energy.32.053006.141119.

Friedlingstein, P., and I. C. Prentice (2010), Carbon-climate feedbacks: A review of model and observation based estimates, Environ. Sustainability, 2, 251-257.

Girardin, M. P., P. Y. Bernier, and S. Gauthier (2011), Increasing potential NEP of eastern boreal North American forests constrained by decreasing wildfire activity, Ecosphere, 2(3), 1-23.

Goetz, S. J., A. G. Bunn, F. J. Fiske, and R. A. Houghton (2005), Satelliteobserved photosynthetic trends across boreal North America Associated with climate and fire disturbance, Proc. Natl. Acad. Sci. U. S. A., 102, 13,521-13,525.

Gu, L., D. D. Baldocchi, S. C. Wofsy, J. W. Munger, S. P. Urbanski, and T. A. Boden (2003), Response of a deciduous forest to the mount Pinatubo eruption: Enhanced photosynthesis, Science, 299, 2035-2038.

Gurney, K. R., et al. (2002), Towards robust regional estimates of $\mathrm{CO}_{2}$ sources and sinks using atmospheric transport models, Nature, 415, 626-630.

Gurney, K. R., D. Baker, P. Rayner, and S. Denning (2008), Interannual variability in continental-scale net carbon exchange and sensitivity to observing networks estimated from atmospheric $\mathrm{CO}_{2}$ inversions for the period 1980 to 2005, Global Biogeochem. Cycles, 22, GB3025, doi:10.1029/ 2007GB003082.

Hicke, J. A., G. P. Asner, J. T. Randerson, C. Tucker, S. Los, R. Birdsey, J. C. Jenkins, and C. Field (2002), Trends in North American net primary productivity derived from satellite observations, 1982-1998, Global Biogeochem. Cycles, 16(2), doi:10.1029/2001GB001550. 


\section{ZHANG ET AL.: REGIONAL CO2 EXCHANGES IN NORTH AMERICA}

$\mathrm{Hu}, \mathrm{Q}$., and S. Feng (2004), Why has the land memory changed?, J. Clim. 17, 3236-3243

Ito, A., and T. Oikawa (2000), A model analysis of the relationship between climate perturbations and carbon budget anomalies in global terrestrial ecosystems: 1970 to 1997, Clim. Res., 15, 161-183.

Kanamitsu, M., W. Ebisuzaki, J. Woollen, S.-K. Yang, J. J. Hnilo, M. Fiorino, and G. L. Potter (2002), NCEP-DEO AMIP-II Reanalysis (R-2), Bull. Am. Meteorol. Soc., 83, 1631-1643.

Keeling, C. D., T. P. Whorf, M. Wahlen, and V. Der Plichtt (1995), Interannual extremes in the rate of rise of atmospheric carbon dioxide since 1980, Nature, 375, 666-670.

Kindermann, J., G. Würth, G. Kohlmaier, and F.-W. Badeck (1996), Interannual variation of carbon exchange fluxes in terrestrial ecosystems, Global Biogeochem. Cycles, 10(4), 737-755.

Kirschbaum, M. U. F. (1995), The T dependence of soil organic matter decomposition and the effect of global warming on soil carbon storage, Soil Biol. Biochem., 27, 753-760.

Krishnan, P., T. A. Black, R. S. Jassal, B. Chen, and Z. Nesic (2009), Interannual variability of the carbon balance of three different-aged Douglas-fir stands in the Pacific Northwest, J. Geophys. Res., 114, G04011, doi:10.1029/ 2008JG000912.

Langenfelds, R. L., R. J. Francey, B. C. Pak, L. P. Steele, J. Lloyd, C. M. Trudinger, and C. E. Allison (2002), Interannual growth rate variations of atmospheric $\mathrm{CO}_{2}$ and its delta $\mathrm{C}-13, \mathrm{H}-2, \mathrm{CH}_{4}$, and $\mathrm{CO}$ between 1992 and 1999 linked to biomass burning, Global Biogeochem. Cycles, 16(3), 1048, doi:10.1029/2001GB001466.

Law, R. M., P. J. Rayner, L. P. Steele, and I. G. Enting (2003), Data and modeling requirements for $\mathrm{CO}_{2}$ inversions using high frequency data, Tellus, 55B, 512-521.

Le Quéré, C., et al. (2009), Trends in the sources and sinks of carbon dioxide, Nat. Geosci., 2, 831-836, doi:10.1038/ngeo689.

Lobell, D. B., J. A. Hicke, G. P. Asner, C. B. Field, C. J. Tucker, and S. O. Los (2002), Satellite estimates of productivity and light use efficiency in Unites States agriculture, 1982-1998, Glob. Change Biol., 8, 722-735.

$\mathrm{Lu}, \mathrm{X}$., and Q. Zhuang (2010), Evaluating climate impacts on carbon balance of the terrestrial ecosystems in the Midwest of the United States with a process-based ecosystem model, Mitigation and Adaptation Strategies for Global Change, 15, 467-487.

Lucht, W., I. C. Prentice, R. B. Myneni, S. Sitch, P. Friedlingstern, W. Cramer, P. Bousquet, W. Buermann, and B. Smith (2002), Climatic Control of the High-latitude vegetation greening trend and Pinatubo effect, Science, 296, 1687-1689.

Mahecha, M. D., et al. (2010), Global convergence in the T sensitivity of respiration at ecosystem level, Science, 329, 838-840.

Matsumura, S., and K. Yamazaki (2012), A longer climate memory carried by soil freeze-thaw processes in Siberia, Environ. Res. Lett., 7, doi:10.1088/ $1748-9326 / 7 / 4 / 045402$

McDowell, N. G., et al. (2008), Mechanisms of plant survival and mortality during drought: Why do some plants survive while others succumb?, New Phytol., 178(4), 719-800.

Myneni, R. B., C. D. Keeling, C. J. Tucker, G. Asrar, and R. R. Nemani (1997), Increased plant growth in the northern high latitudes from 1981 to 1991, Nature, 386, 698-702.

Nemani, R., M. White, P. Thornton, K. Nishida, S. Reddy, J. Jenkins, and S. Running (2002), Recent trends in hydrologic balance have enhanced the terrestrial carbon sink in the United States, Geophys. Res. Lett., 29(10), doi:10.1029/2002GL014867.

Pacala, S. W., et al. (2001), Consistent land-and-atmosphere-based U.S. carbon sink estimates, Science, 292, 2316-2320.

Patra, P. K., M. Ishizawa, S. Maksyutov, T. Nakazawa, and G. Inoue (2005), Role of biomass burning and climate anomalies for land-atmosphere carbon fluxes based on inverse modeling of atmospheric $\mathrm{CO}_{2}$, Global Biogeochem. Cycles, 19, GB3005, doi:10.1029/2004GB002258.

Patra, P. K., S. E. Mikaloff-Fletcher, K. Ishijima, S. Maksyutov, and T. Nakazawa (2006), Comparison of $\mathrm{CO}_{2}$ fluxes estimated using atmospheric and oceanic inversions, and role of fluxes and their interannual variability in simulating atmospheric $\mathrm{CO}_{2}$ concentrations, Atmos Chem. Phys. Discuss., 6, 6801-6823.

Peylin, P., P. Bousquet, C. Le Quéré, S. Sitch, P. Friedlingstein, G. McKinley, N. Gruber, P. Rayner, and P. Ciais (2005). Multiple constraints on regional $\mathrm{CO}_{2}$ flux variations over land and oceans, Global Biogeochem. Cycles, 19, GB1011, doi:10.1029/2003GB002214.

Peylin, P., et al. (2013), Global atmospheric carbon budget: results from an ensemble of atmospheric $\mathrm{CO}_{2}$ inversion, Biogeosci. Discuss., 10, 5301-5360.

Piao, S., et al. (2008), Net carbon dioxide losses of northern ecosystems in response to autumn warming, Nature, 451, 49-53.

Potter, C., S. Boriah, M. Steinbach, V. Kumar, and S. Klooster (2003), Terrestrial vegetation dynamics and global climate controls in North America: 2001-05, Earth Interact., 12, 1-12.

Randerson, J. T., et al. (2006), The impact of boreal forest fire on climate warming, Science, 314, 1130-1132.

Rayner, P. J., R. M. Law, C. E. Allison, R. J. Francey, C. M. Trudinger, and C. Pickett-Heaps (2008), Interannual variability of the global carbon cycle (1992-2005) inferred by inversion of atmospheric $\mathrm{CO}_{2}$ and $\mathrm{d} 13 \mathrm{CO}_{2}$ measurements, Global Biogeochem. Cycles, 22, GB3008, doi:10.1029/ $2007 \mathrm{~GB} 003068$.

Röedenbeck, C., S. Houweling, M. Gloor, and M. Heimann (2003), $\mathrm{CO}_{2}$ flux history 1982-2001 inferred from atmospheric data using a global inversion of atmospheric transport, Atmos. Chem. Phys., 3, 1919-1964.

Schaefer, K., A. S. Dennning, N. Suits, J. Kaduk, I. Baker, S. Los, and L. Prihodko (2002), Effect of climate on interannual variability of terrestrial $\mathrm{CO}_{2}$ fluxes, Global Biogeochem. Cycles 16(4), 1102, doi: 10.1029/ 2002GB001928.

Schaefer, K. M., T. Zhang, P. P. Tans, and R. Stöckli (2007), Temperature anomaly reemergence in seasonally frozen soils, J. Geophys. Res., 112, D20102, doi:10.1029/2007JD008630.

Schwalm, C. R., C. A. Williams, K. Schaefer, I. Baker, G. J. Collatz, and C. Rödenbeck (2011), Does terrestrial drought explain global $\mathrm{CO}_{2}$ flux anomalies induced by El Niño?, Biogeosciences, 8 , $2493-2506$.

Seager, R. (2007), The turn of the century North American Drought: Global Context, Dynamics, and past Analogs, J. Clim., 20, 5527-5552.

Van Mantgem, P. J., et al. (2009), Widespread increase of tree mortality rates in the western United States, Science, 323, 521-524.

Wang, X., S. Piao, P. Ciais, J. Li, P. Friedlingstein, C. Koven, and A. Chen (2011), Spring T change and its implication in the change of vegetation growth in North America from 1982 to 2006, Proc. Natl. Acad. Sci. U.S. A., 108, 1240-1245.

Welp, L. R., J. T. Randerson, and H. P. Liu (2007), The sensitivity of carbon fluxes to spring warming and summer drought depends on plant functional type in boreal forest ecosystems, Agri. For. Meteorol., 147, 172-185.

Westerling, A. L., H. G. Hidalgo, D. R. Cayan, and T. W. Swetnam (2006), Warming and earlier spring increase western U.S. forest wildfire activity, Science, 313, 940-943.

Yi, C., et al. (2010), Climate control of terrestrial carbon exchange across biomes and continent, Environ. Res. Lett., 5, doi:10.1088/1748-9326/5/ $3 / 034007$.

Zeng, N., A. Mariotti, and P. Wetzel (2005), Terrestrial mechanisms of interannual $\mathrm{CO}_{2}$ variability, Global Biogeochem. Cycles, 19, GB1061, doi:10.1029/2004GB002273.

Zhang, K., J. S. Kimball, E. H. Hogg, M. Zhao, W. C. Oechel, J. J. Cassano, and S. W. Running (2008), Satellite-based model detection of recent climate-driven changes in northern high-latitude vegetation productivity. J. Geophys. Res. 113, G03033, doi:10.1029/2007JG000621.

Zhang, X., M. Goldberg, D. Tarpley, M. A. Friedl, J. Morisette, F. Kogan, and Y. Yu (2010), Drought-induced vegetation stress in southwestern North America, Environ. Res. Lett., 5, doi:10.1088/1748-9326/5/2/ 024008

Zhou, L., R. K. Kaufmann, Y. Tian, R. B. Myneni, and C. J. Tucker (2003), Relation between interannual variations in satellite measures of northern forest greenness and climate between 1982 and 1999, J. Geophys. Res., 108, doi:10.1029/2002JD002510. 